\title{
The 5'-AMP-Activated Protein Kinase Regulates the Function and Expression of Human Organic Anion Transporting Polypeptide $1 \mathrm{~A} 2^{\text {[ }}$
}

\author{
Xiaoxi Lu, Ting Chan, Zhengqi Cheng, Tahiatul Shams, Ling Zhu, Michael Murray, \\ and Fanfan Zhou
}

School of Pharmacy (X.L., T.C., Z.C., T.S., F.Z.), Save Sight Institute (L.Z.), and Discipline of Pharmacology (M.M.), Faculty of Medicine and Health, University of Sydney, New South Wales, Australia; and Japanese Foundation for Cancer Research, Koto-ku, Tokyo, Japan (T.C.)

Received June 20, 2018; accepted September 28, 2018

\section{ABSTRACT}

The organic anion transporting polypeptides (OATPs) are important membrane proteins that mediate the cellular uptake of drugs and endogenous substances. OATP1A2 is widely distributed in many human tissues that are targeted in drug therapy; defective OATP1A2 leads to altered drug disposition influencing therapeutic outcomes. 5'-AMP-activated protein kinase (AMPK) signaling plays an important role in the pathogenesis of the metabolic syndrome characterized by an increased incidence of type II diabetes and nonalcoholic fatty liver disease. This study investigated the regulatory role of AMPK in OATP1A2 transport function and expression. We found that the treatment of AMPK-specific inhibitor compound C (dorsomorphin dihydrochloride) decreased OATP1A2mediated uptake of estrone-3-sulfate in a concentration- and time-dependent manner. The impaired OATP1A2 function was associated with a reduced $V_{\max }[154.6 \pm 17.9 \mathrm{pmol} \times(\mu \mathrm{g} \times$ 4 minutes $)^{-1}$ in compound C-treated cells vs. $413.6 \pm$ $52.5 \mathrm{pmol} \times(\mu \mathrm{g} \times 4 \text { minutes })^{-1}$ in controls]; the $\mathrm{K}_{\mathrm{m}}$ was unchanged. The cell-surface expression of OATP1A2 was decreased by compound $\mathrm{C}$ treatment, but total cellular expression was unchanged. The impaired cell-surface expression of OATP1A2 was associated with accelerated internalization and impaired targeting/recycling. Silencing of the AMPK $\alpha 1$-subunit using specific small interfering RNA corroborated the findings with compound $C$ and revealed a role for AMPK in regulating OATP1A2 protein stability. Overall, this study implicated AMPK in the regulation of the function and expression of OATP1A2, which potentially impacts on the disposition of OATP1A2 drug substrates that may be used to treat patients with the metabolic syndrome and other diseases.

\section{Introduction}

Solute carrier transporters (SLCs) mediate the uptake of organic ions, amino acids, nucleotides, fatty acids, and drugs into cells (Hediger et al., 2004). Within the $S L C$ family, the $S L C O$ subfamily, which encodes the Organic Anion Transporting Polypeptides (OATPs), is particularly important in drug disposition (Zhou et al., 2017). Of the 11 human OATP isoforms that have been identified, OATP1A2, 1B1, 1B3, and $2 \mathrm{~B} 1$ are the best characterized and are abundantly present in the intestine, liver, kidney, and other tissues, where they facilitate drug absorption, distribution, and elimination (Kullak-Ublick et al., 1995; Kim, 2003; Steckelbroeck et al., 2004; Zhou et al., 2017).

OATPs are regulated at the transcriptional and posttranslational levels. In human breast cancer cells, OATP1A2

This work was supported by the National Health and Medical Research Council of Australia [Grant APP1025101].

The authors state no conflict of interest.

https://doi.org/10.1124/mol.118.113423.

S This article has supplemental material available at molpharm. aspetjournals.org. gene transcription is activated by pregnane $\mathrm{X}$ receptor agonists, such as rifampin (Jigorel et al., 2006; Ma et al., 2007; Meyer zu Schwabedissen et al., 2008). The subcellular trafficking, recycling, and internalization of OATP1A2 are regulated at the post-translational level; these processes play a major role in the expression of active transporter at the cell surface. Several protein kinases regulate OATP1A2 expression at the plasma membrane. For example, protein kinase $\mathrm{C}$ (PKC) modulates the plasma membrane expression and function of OATP1A2, as well as OATP1B1 and OATP2B1, by regulating protein trafficking (Köck et al., 2010; Zhou et al., 2011; Hong et al., 2015). In addition, casein kinase 2 (CKII) emerged recently as an important kinase that regulates the protein subcellular trafficking of OATP1A2 (Chan et al., 2016).

The 5'-adenosine monophosphate-activated kinase (AMPK) is a cellular energy sensor in eukaryotic cells (Hardie et al., 2012). AMPK is a heterotrimeric complex that is composed of a catalytic $\alpha$-subunit (either the $\alpha 1$ or $\alpha 2$ isoform), a $\beta$-subunit (either $\beta 1$ or $\beta 2$ ), and a $\gamma$-subunit $(\gamma 1, \gamma 2$, or $\gamma 3$ ); the subunit composition of AMPK is distinct in different tissues, which is also associated with diverse kinase activity and stability

ABBREVIATIONS: AICIR, 5-Aminoimidazole-4-carboxamide ribonucleotide; AMPK, 5'-AMP-activated protein kinase; CKII, casein kinase 2; compound $\mathrm{C}$, dorsomorphin dihydrochloride; E3S, estrone-3-sulfate; HEK, human embryonic kidney; OATP, organic anion transporting polypeptide; PBS, phosphate-buffered saline; PKC, protein kinase C; SLC, solute carrier transporter. 
(Russo et al., 2013). AMPK regulates genes, such as acetyl-CoA carboxylase and 3-hydroxy-3-methylglutaryl-CoA reductase, that mediate the biosynthesis of nutrient fatty acids and cholesterol, respectively (Beg et al., 1973; Carlson and Kim, 1973). AMPK also regulates metabolic homeostasis by activating energy production and increasing insulin sensitivity (Hardie, 2011b; Coughlan et al., 2014). AMPK dysregulation occurs in obesity, type II diabetes, and the metabolic syndrome (Steinberg and Kemp, 2009; Coughlan et al., 2013, 2014; O’Neill et al., 2013), whereas activating AMPK is the current therapeutic approach in treating such diseases (Coughlan et al., 2014). Drug transporters are known to be impaired in nonalcoholic fatty liver disease, which is a component of the metabolic syndrome, due in part to dysregulated $N$-glycosylation (Clarke et al., 2017). In this study, we found that OATP1A2 is regulated by AMPK, and a series of experiments were undertaken to evaluate in greater detail the regulatory role of $\mathrm{AMPK}$ in the function and expression of major OATP drug transporters because of its potential significance to drug therapy in patients with the metabolic syndrome.

\section{Materials and Methods}

Materials. $\left[{ }^{3} \mathrm{H}\right]$-Estrone-3-sulfate (E3S; specific activity $57.3 \mathrm{Ci} /$ mmol) was purchased from PerkinElmer (Melbourne, VIC, Australia). Cell culture medium was obtained from Thermo Scientific (Lidcombe, NSW, Australia). Unless otherwise stated, compound C (dorsomorphin dihydrochloride) and all other chemicals and biochemicals were purchased from Sigma-Aldrich (Castle Hill, NSW, Australia).

Generation of Human Embryonic Kidney-293T Cells that Overexpress OATP Isoforms. The C-terminal Flag (DYKDDDDK)tagged OATP1A2-, OATP1B1-, OATP1B3-, and OATP2B1-containing plasmids were purchased or constructed in house as described previously (Zhou et al., 2011, 2013; Xu et al., 2013; Zheng et al., 2014; Shams et al., 2018). Human embryonic kidney (HEK)-293T cells were maintained in Dulbecco's modified Eagle's medium supplemented with $10 \%$ fetal calf serum and $1 \%$ L-glutamine at $37^{\circ} \mathrm{C}$ in a $5 \% \mathrm{CO}_{2}$ atmosphere. Cells were transfected using Lipofectamine 2000 (Thermo Scientific) following the manufacturer's instructions. In some experiments, HEK-293T cells were transfected with AMPK $\alpha 1$-subunitspecific small interfering RNAs (small interfering RNAs, Cat. No. sc-29673; Bio-strategy Laboratory Products, Tingalpa, QLD, Australia) or scrambled small interfering RNAs (Cat. No. sc-37007; Bio-strategy Laboratory Products) using Lipofectamine 2000. Twenty-four hours after transfection, transporter function and protein expression were assessed.

Transport Uptake Assays. Uptake of $\left[{ }^{3} \mathrm{H}\right]$-E3S (300 nM; 57.3 $\mathrm{nCi} /$ well) by OATP1A2-, OATP1B1-, and OATP2B1-expressing cells and uptake of $\left[{ }^{3} \mathrm{H}\right]$-cholecystokinin- 8 (2 $\mathrm{nM} ; 23.4 \mathrm{nCi} /$ well $)$ by OATP1B3-expressing cells were conducted at $37^{\circ} \mathrm{C}$ in phosphatebuffered saline (PBS; $137 \mathrm{mM} \mathrm{NaCl}, 2.7 \mathrm{mM} \mathrm{KCl}, 4.3 \mathrm{mM} \mathrm{Na} 2 \mathrm{HPO}_{4}$, $1.4 \mathrm{mM} \mathrm{KH}_{2} \mathrm{PO}_{4}, \mathrm{pH} 7.4$ ) containing $5 \mathrm{mM}$ glucose. Eight minutes was selected for transporter uptake assays and 4 minutes for kinetic experiments, as described previously (Johnston et al., 2014; Chan et al., 2015a; Lu et al., 2018; Shams et al., 2018). Uptake was terminated by rapidly washing cells in ice-cold PBS. Cells were then incubated with $0.2 \mathrm{M} \mathrm{NaOH}$ at room temperature for 20 minutes, followed by $0.2 \mathrm{M} \mathrm{HCl}$ for 20 minutes, before aliquots were taken for liquid scintillation counting. Control uptake rates by vectortransfected cells were subtracted from all data. In kinetic studies, the E3S concentration range was $0.05-50 \mu \mathrm{M}$ and apparent $\mathrm{K}_{\mathrm{m}}$ and $\mathrm{V}_{\max }$ values for uptake were calculated using GraphPad Prism 5.0 (GraphPad Inc., La Jolla, CA). Data were derived in three independent experiments with triplicate repeats for each treatment.

Cell Surface Biotinylation. The membrane-impermeable biotinylation reagent NHS-SS-biotin (Thermo Scientific) was used to determine the cell-surface expression of OATP1A2, as described before (Zhou et al., 2010, 2011, 2013; Zheng et al., 2014; Chan et al.,
2016). After three washes with ice-cold PBS ( $\mathrm{pH}$ 8.0), cells were incubated on ice with freshly prepared NHS-SS-biotin $(0.5 \mathrm{mg} / \mathrm{ml})$ for 30 minutes, then washed three times with PBS containing $100 \mathrm{mM}$ glycine and twice with cold PBS. Cells were lysed with radioimmunoprecipitation assay buffer ( $10 \mathrm{mM}$ Tris, $150 \mathrm{mM} \mathrm{NaCl}, 1 \mathrm{mM}$ EDTA, $0.1 \%$ SDS, $1 \%$ Triton X-100 containing protease inhibitor cocktail, Cat. No. R-1101; Sapphire Biosciences, Redfern, NSW, Australia). Following centrifugation at $14,000 \mathrm{~g}\left(4^{\circ} \mathrm{C}\right)$, streptavidin-conjugated agarose beads (Thermo Scientific) were added to lysates to capture membrane-bound proteins. Proteins were eluted from beads in Laemmli buffer and subjected to SDS-polyacrylamide gel electrophoresis.

Internalization Assay. As shown in Supplemental Fig. 1A, the internalization of biotinylated OATP1A2 was evaluated in untreated HEK-293T cells, or cells that were pretreated with compound C (10 $\mu \mathrm{M}$, 1 hour, $37^{\circ} \mathrm{C}$ ) (Zhou et al., 2011; Zheng et al., 2014; Chan et al., 2016). As described earlier, cells were warmed to $37^{\circ} \mathrm{C}$ to initiate internalization for varying times following NHS-SS-biotin prelabeling. Sodium 2 -mercaptoethanesulfonate $(100 \mathrm{mM})$ was then added in nick translation buffer ( $150 \mathrm{mM} \mathrm{NaCl}, 1 \mathrm{mM}$ EDTA, $0.2 \%$ bovine serum albumin, $20 \mathrm{mM}$ Tris, $\mathrm{pH}$ 8.6) to remove residual biotinylated, but noninternalized, proteins that remained at the cell surface. After washing with cold PBS (five times), cells were lysed and streptavidinagarose beads were added to capture biotinylated proteins that had been internalized.

Targeting Assay. We assessed the plasma membrane targeting of newly synthesized OATP1A2 protein in combination with OATP1A2 protein that had been internalized and recycled back to the plasma membrane (Supplemental Fig. 1B). OATP1A2-overexpressing HEK$293 \mathrm{~T}$ cells were incubated in the presence and absence of compound $\mathrm{C}\left(10 \mu \mathrm{M}, 1\right.$ hour, $\left.37^{\circ} \mathrm{C}\right)$ (Zhou et al., 2011; Zheng et al., 2014; Chan et al., 2016) and then labeled with NHS-SS-biotin. Cells were then warmed to $37^{\circ} \mathrm{C}$ to initialize recycling/targeting for varying times, and an additional aliquot of NHS-SS-biotin $(0.5 \mathrm{mg} / \mathrm{ml}, 30$ minutes) was added to further label the proteins newly recycled/targeted to the cell surface. Residual NHS-SS-biotin was quenched with glycine and cells were lysed as described earlier. Following centrifugation, equivalent quantities (300 $\mu \mathrm{g}$ of protein/sample) of lysates from individual cell incubations were loaded onto streptavidin-agarose beads and subjected to electrophoresis and immunoblotting for OATP1A2. The quantity of recycled/targeted OATP1A2 at multiple time points was determined relative to initially biotinylated OATP1A2.

Recycling Assay. HEK-293T cells that overexpressed OATP1A2 were pretreated with compound $\mathrm{C}\left(10 \mu \mathrm{M}, 1\right.$ hour, $\left.37^{\circ} \mathrm{C}\right)$. After an initial biotinylation, the residual NHS-SS-biotin was quenched on ice with glycine, and the cells were then warmed to $37^{\circ} \mathrm{C}$ for 1 minute to initialize internalization (Supplemental Fig. 1C). Sodium 2-mercaptoethanesulfonate $(100 \mathrm{mM})$ in nick translation buffer was added to remove biotinylated, but noninternalized, proteins that remained at the cell surface. The cells were again warmed to $37^{\circ} \mathrm{C}$ to initiate recycling for varying times. At intervals, the cells were treated with sodium 2-mercaptoethanesulfonate for a second time to remove biotinylated and proteins that had been recycled to the cell surface. Cell lysates were prepared and streptavidin-agarose beads were added to isolate biotinylated proteins. The relative quantity of recycled OATP1A2 was calculated as the difference between the biotinylation signals after the first and second treatments with sodium 2-mercaptoethanesulfonate (total internalized protein and internalized, but not recycled, protein, respectively).

Electrophoresis and Immunoblotting. Protein samples were denatured at $50^{\circ} \mathrm{C}$ for 30 minutes, loaded onto $7.5 \%$ polyacrylamide minigels, and electrophoresed (Bio-Rad, Gladesville, NSW, Australia). After transfer to polyvinylidene fluoride membranes in an electroelution cell (Bio-Rad), the membranes were blocked with 5\% nonfat dry milk in phosphate buffered saline with Tween-20 $(137 \mathrm{mM} \mathrm{NaCl}$, $2.7 \mathrm{mM} \mathrm{KCl}, 4.3 \mathrm{mM} \mathrm{Na}_{2} \mathrm{HPO}_{4}, 1.4 \mathrm{mM} \mathrm{KH}_{2} \mathrm{PO}_{4}$, and $0.05 \%$ Tween 20 , $\mathrm{pH}$ 7.5) for 30 minutes at room temperature. Membranes were subsequently washed with phosphate buffered saline with Tween-20 and incubated with anti-Flag primary antibody (Cat. No. 2368S, 
A

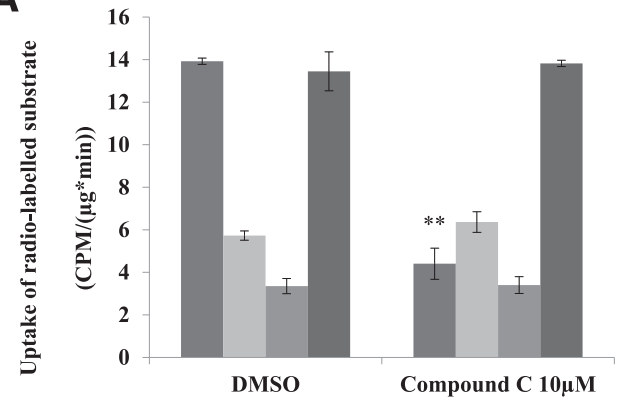

C

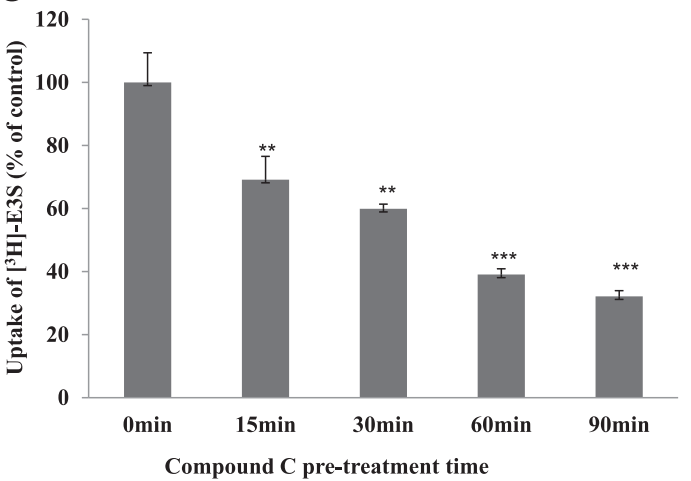

B

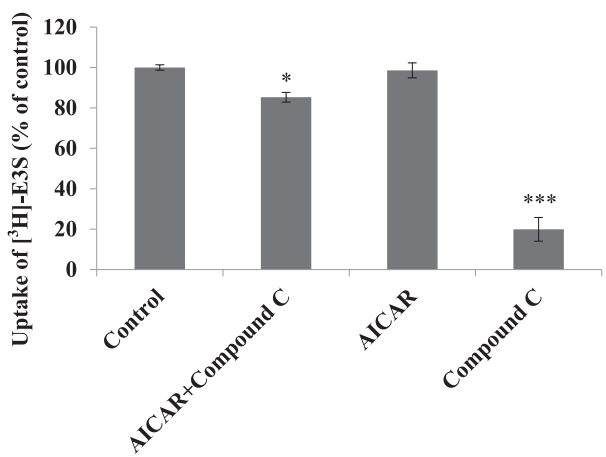

D

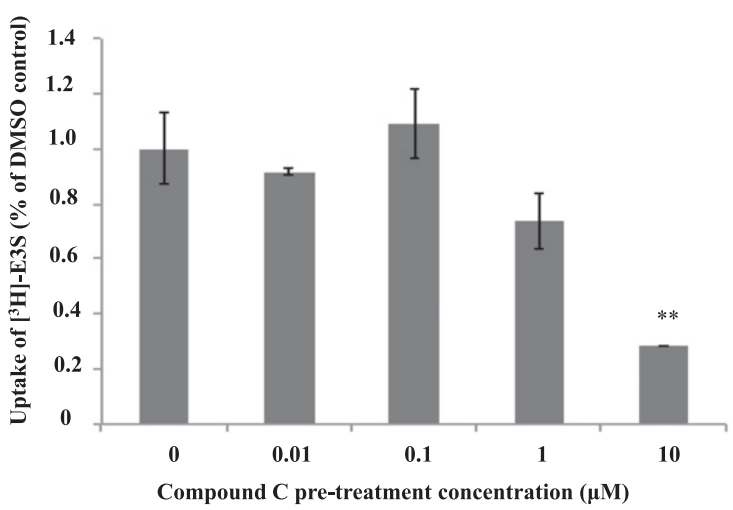

Fig. 1. Effect of AMPK inhibition on $\left[{ }^{3} \mathrm{H}\right]$-E3S uptake by HEK-293T cells that overexpressed OATP isoforms. (A) Substrate uptake by OATP1A2, OATP1B1, OATP2B1, and OATP1B3 in overexpressing HEK-293T cells in the presence or absence of compound $\mathrm{C}\left(10 \mu \mathrm{M}, 37^{\circ} \mathrm{C}, 60 \mathrm{minutes}\right)$. Uptake of $\left[{ }^{3} \mathrm{H}\right]$-E3S $(300 \mathrm{nM})$ was used for OATP1A2, OATP1B1, and OATP2B1; uptake of $\left[{ }^{3} \mathrm{H}\right]$-cholecystokinin-8 $(2 \mathrm{nM})$ was used for OATP1B3, as described in the Materials and Methods. (B) AMPK activator 5-aminoimidazole-4-carboxamide ribonucleotide (AICAR) reverses the inhibitory effect of compound C on OATP1A2-mediated $\left[{ }^{3} \mathrm{H}\right]$-E3S uptake. OATP1A2 overexpressing HEK-293T cells were pretreated with or without AICAR $\left(2 \mathrm{mM}, 37^{\circ} \mathrm{C}, 30 \mathrm{minutes}\right)$ followed by treatment with compound $\mathrm{C}\left(10 \mu \mathrm{M}, 37^{\circ} \mathrm{C}, 60\right.$ minutes). Uptake of $\left[{ }^{3} \mathrm{H}\right]-\mathrm{E} 3 \mathrm{~S}(300 \mathrm{nM})$ used for OATP1A2 was measured as described in the Materials and Methods. (C) Effect of duration of treatment of OATP1A2-overexpressing HEK-293T cells with compound $\mathrm{C}\left(10 \mu \mathrm{M}, 37^{\circ} \mathrm{C}\right)$ on $\left[{ }^{3} \mathrm{H}\right]-\mathrm{E} 3 \mathrm{~S}$ uptake (300 nM). (D) Effect of compound C concentration on $\left[{ }^{3} \mathrm{H}\right]$-E3S $(300 \mathrm{nM})$ uptake by OATP1A2-overexpressing HEK-293T cells $\left(60 \mathrm{minutes}\right.$, $\left.37^{\circ} \mathrm{C}\right)$. Values are the mean \pm S.D. $(n=3) .{ }^{*} P<0.05$; $* * P<0.01$; $* * P<0.005$; different from DMSO-control. CPM, counts per minute; DMSO, dimethylsulfoxide.

$1 \mu \mathrm{g} / \mathrm{ml}$; Genesearch Pty. Ltd., Arundel, QLD, Australia) at $4^{\circ} \mathrm{C}$ overnight. After washing, blots were incubated with horseradish peroxidase-conjugated goat anti-rabbit IgG (Cat. No. sc-2004, 1: 5000; Bio-Strategy Laboratory Products, Melbourne, VIC, Australia) for 1 hour at room temperature. Signals were then detected using the SuperSignal West Pico Chemiluminescent Substrate (Thermo Scientific). Densitometry analysis was conducted using ImageJ software (National Institutes of Health, Bethesda, MD).

Statistics. Student's $t$ test was used to compare two groups of normally distributed data. Differences in transport activity with or without compound $\mathrm{C}$ (multiple groups) were detected by one-way analysis of variance and Dunnett's test. Data are presented as the mean \pm S.D. with a $P$ value $<0.05$ considered as statistically significant.

\section{Results}

Selective Modulation of OATP1A2-Dependent Transporter Activity by AMPK Inhibition. In initial experiments, HEK-293T cells that overexpressed OATP1A2, OATP1B1, OATP1B3, or OATP2B1 were treated with the AMPK inhibitor compound $\mathrm{C}(10 \mu \mathrm{M})$ for 1 hour, and then transport uptake was estimated. Compound $\mathrm{C}$ is the widely used, commercially available, cell-permeable AMPK-specific inhibitor with a $\mathrm{K}_{i}$ of $109 \mathrm{nM}$ (Handa et al., 2011). As shown in Fig. 1A, compound $\mathrm{C}$ selectively impaired OATP1A2 transport activity but not that of the other three OATPs. It is known that compound $\mathrm{C}$ can also inhibit other signaling factors, but it has no significant inhibitory effect on kinases structurally related to AMPK (Liu et al., 2014). We pretreated the cells with AMPK activator 5-Aminoimidazole-4-carboxamide ribonucleotide (AICAR) prior to the compound C incubation (Fig. 1B). We found that AICAR can pronouncedly reverse the effect of compound $\mathrm{C}$, which suggested the specific regulatory role of AMPK in OATP1A2.

In further studies, the time and concentration dependence of compound $\mathrm{C}$ treatment on OATP1A2 transporter function was assessed (Fig. 1, C and D). Pronounced decreases in E3S uptake were produced by 15-90 minutes of treatment with $10 \mu \mathrm{M}$ compound $\mathrm{C}$. Kinetic studies showed that AMPK inhibition decreased the $\mathrm{V}_{\max }$ for E3S uptake relative to control $\left[154.6 \pm 17.9 \mathrm{pmol} \cdot(\mu \mathrm{g} \times 4 \text { minute })^{-1}\right.$ vs. $413.6 \pm$ $52.5 \mathrm{pmol}(\mu \mathrm{g} \times 4 \text { minute })^{-1}$ ], whereas the $\mathrm{K}_{\mathrm{m}}$ after compound $\mathrm{C}$ treatment was unchanged from control $(44.1 \pm 9.2 \mathrm{vs} .63 .9 \pm$ $12.9 \mu \mathrm{M}$; Fig. 2).

AMPK Inhibition Impacts on the Expression of OATP1A2 at the Plasma Membrane. The decreased $V_{\max }$ of OATP1A2-mediated E3S uptake after treatment with compound $\mathrm{C}$ could be due to impaired transporter expression at the cell surface; this was tested directly in further studies. At the plasma membrane, OATP1A2 immunoreactive protein is present as the fully $N$-glycosylated mature isoform $(\sim 95 \mathrm{kDa})$; at intracellular locations, a partially $N$-glycosylated immature isoform $(\sim 60 \mathrm{kDa})$ is also present in addition to the 95-kDa isoform (Zhou et al., 2011, 2013; Zheng et al., 2014; Chan et al., 2016). It was found that AMPK inhibition 
A

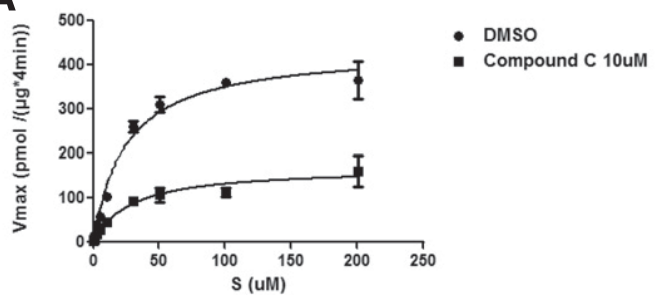

B

\begin{tabular}{|l|l|l|}
\hline & $\mathbf{K}_{\mathrm{m}}(\boldsymbol{\mu M})$ & $\mathbf{V}_{\max }\left[\mathbf{p m o l} \mathbf{x}(\boldsymbol{\mu g} \mathbf{x} \mathbf{4} \mathbf{~ m i n})^{-1}\right]$ \\
\hline DMSO & $63.9 \pm 12.9$ & $413.6 \pm 52.5$ \\
\hline Compound C 10 $\boldsymbol{\mu M}$ & $44.1 \pm 9.1$ & $154.6 \pm 17.9^{* *}$ \\
\hline
\end{tabular}

Fig. 2. Kinetic analysis of $\left[{ }^{3} \mathrm{H}\right]$-E3S uptake by HEK-293T cells that overexpressed OATP1A2 in the presence or absence of compound C. $\left[{ }^{3} \mathrm{H}\right]$-E3S concentrations ranged from 0.05 to $50 \mu \mathrm{M}$ (4-minute uptake); cells were treated with $10 \mu \mathrm{M}$ compound $\mathrm{C}$ or DMSO for 60 minutes at $37^{\circ} \mathrm{C}$. Transporter kinetic parameters $\left(\mathrm{K}_{\mathrm{m}}\right.$ and $\left.\mathrm{V}_{\max }\right)$ were calculated using GraphPad Prism 5. Values are the mean \pm S.D. $(n=3)$. (A) MichaelisMenten plot. (B) Calculated $\mathrm{K}_{\mathrm{m}}$ and $\mathrm{V}_{\max }$ values of OATP1A2. ${ }^{* *} P<0.01$, different from dimethylsulfoxide (DMSO)-control.

by compound $\mathrm{C}$ impaired the cell-surface expression of OATP1A2 (Fig. 3, A and B) but had no effect on total OATP1A2 expression (Fig. 3, C and D).

AMPK Regulates Subcellular Trafficking of OATP1A2. Previous studies have shown that OATP1A2 is trafficked continuously between the cell surface and intracellular compartments (Zhou et al., 2011; Zheng et al., 2014; Chan et al., 2016). Trafficking processes include internalization from the cell surface to intracellular compartments, recycling from intracellular compartments back to the cell surface, and targeting of newly synthesized protein to the cell surface. We conducted biotinylation-based assays to investigate the effect of AMPK inhibition on OATP1A2 trafficking, in particular internalization, recycling, and targeting.

As shown in Fig. 4A, AMPK inhibition accelerated the internalization of OATP1A2 from the cell surface to intracellular compartments. In addition, the rate at which OATP1A2 protein was trafficked from intracellular compartments back to the cell surface and the recycling of OATP1A2 were impaired by AMPK inhibition (Fig. 4, B and C).

AMPK Silencing Modulates OATP1A2 Activity and Expression. As mentioned, heterotrimeric AMPK consists of a catalytic $\alpha$-subunit and regulatory $\beta$ - and $\gamma$-subunits (Mihaylova and Shaw, 2011). We also adopted an independent approach from chemical inhibition to verify the specific regulatory role of AMPK on OATP1A2. Knockdown of the AMPK $\alpha$-subunit has been shown to disrupt AMPK signaling in HEK-293T cells (Tzatsos and Tsichlis, 2007; Tangeman et al., 2012). In the present study, we used small interfering RNA silencing of the AMPK $\alpha 1$-subunit to corroborate and extend the findings with compound $\mathrm{C}$ on OATP1A2 regulation. Following AMPK $\alpha 1$ silencing, E3S uptake was decreased in HEK-293T cells to $\sim 6.1 \%$ of control scrambled small interfering RNA-transfected cells $(P<0.001$, Fig. 5B). Similar to compound $\mathrm{C}$ treatment, such AMPK $\alpha 1$ silencing decreased the expression of OATP1A2 at the plasma membrane (Fig. 5, C and D). Such observation was also validated with another independent small interfering RNA obtained from Thermo Scientific (Supplemental Fig. 2). However, unlike AMPK inhibition, AMPK $\alpha 1$ silencing also appeared to decrease protein stability (Fig. 5, C and D). The additional effect of small interfering RNA silencing on OATP1A2 protein stability is possibly due to the long-term effect of AMPK inhibition (48 hours after cotransfection of OATP1A2 and AMPK $\alpha 1$
A

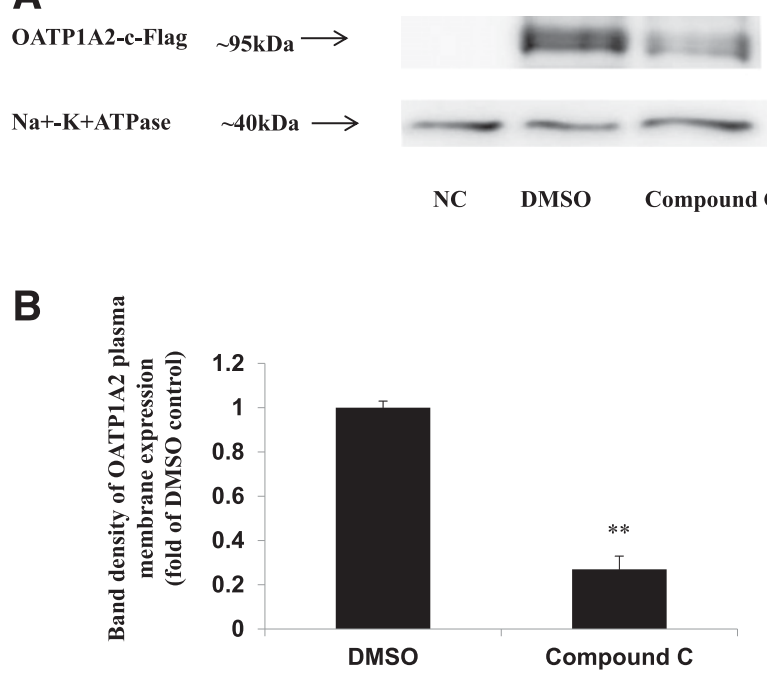

C

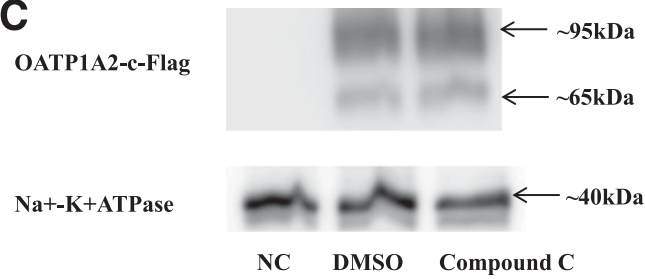

D

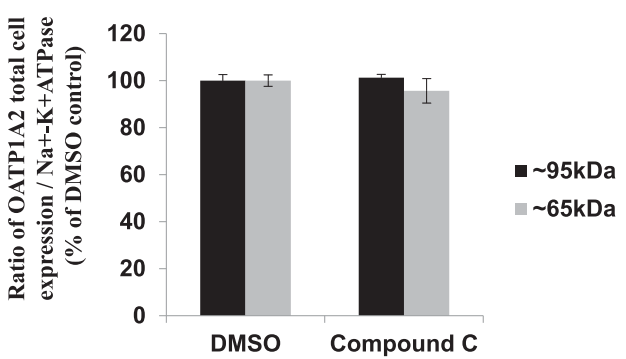

Fig. 3. Effect of AMPK inhibition on OATP1A2 protein expression. (A) Cell-surface expression of OATP1A2 with or without compound C pretreatment assessed with biotinylation assay. Overexpressing HEK-293T cells were pretreated with compound C (10 $\mu$ M) or dimethylsulfoxide (DMSO) for 60 minutes at $37^{\circ} \mathrm{C}$. (Top) Protein lysate probed with anti-Flag antibody. (Bottom) After stripping, the blot was reprobed with anti-Na ${ }^{+}-\mathrm{K}^{+}-\mathrm{ATPase}^{-}$ antibody. (B) Densitometric analysis of OATP1A2 cell-surface expression. Data were derived in three independent experiments. Values are the mean \pm S.D. $(n=3) .{ }^{*} * P<0.01$, different from DMSO-control. (C) Total cellular expression of immunoreactive OATP1A2 with or without compound C pretreatment. Overexpressing HEK-293T cells were pretreated with compound C (10 $\mu \mathrm{M})$ or DMSO for 60 minutes at $37^{\circ} \mathrm{C}$. (Top) Protein lysate probed with anti-Flag antibody. (Bottom) After stripping, the blot was reprobed with anti- $\mathrm{Na}^{+}-\mathrm{K}^{+}$-ATPase antibody. (D) Densitometry analysis of protein total cell expression. Data were derived in three independent experiments. Values are the mean \pm S.D. $(n=3)$. NC, vector-transfected HEK-293T cells. 
A

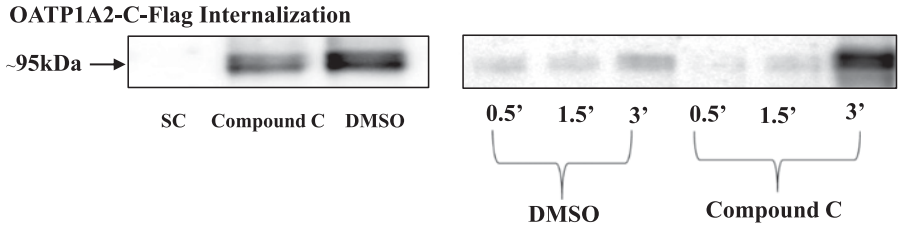

C

OATP1A2-C-Flag Targeting

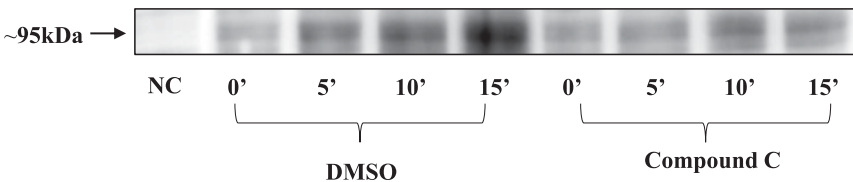

E

OATP1A2-C-Flag Recycling

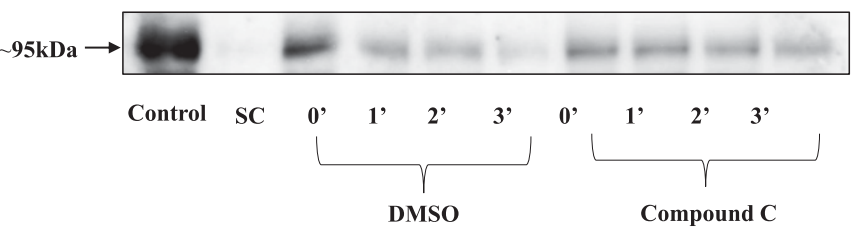

B
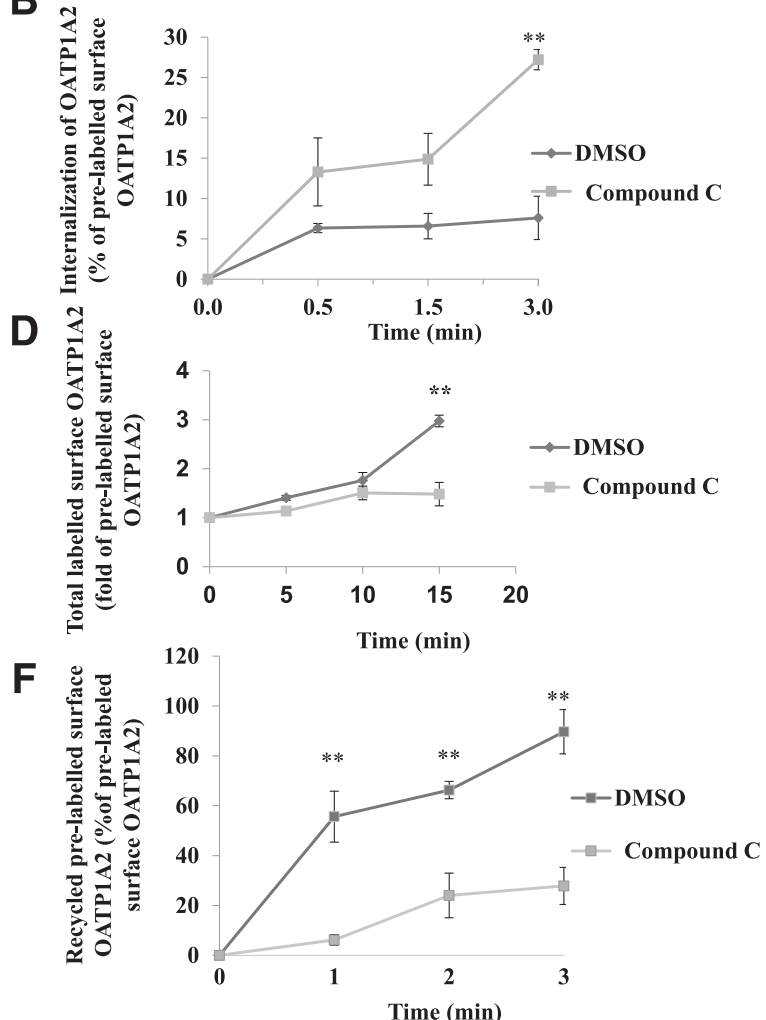

Fig. 4. Protein trafficking of OATP1A2 in the overexpressing HEK-293T cells with or without compound C treatment. (A) OATP1A2 internalization process. (Left) OATP1A2 internalization assay was conducted as described in the Materials and Methods. Cells were pretreated with compound C or dimethylsulfoxide (DMSO; $10 \mu \mathrm{M}, 60$ minutes, $37^{\circ} \mathrm{C}$ ). Cells were allowed to internalize for $0.5,1.5$, and 3 minutes at $37^{\circ} \mathrm{C}$. (Right) Densitometric analysis of the internalized transporter protein as a percentage of the total initially biotinylated OATP1A2 at the cell surface. (B) OATP1A2 membrane-targeting process. (Left) OATP1A2 targeting was evaluated as described in the Materials and Methods. Cells were pretreated with compound C or DMSO (10 $\mu$ M, 60 minutes, $37^{\circ} \mathrm{C}$ ). Additional biotin labeling was allowed for 5,10 , and 15 minutes at $37^{\circ} \mathrm{C}$. (Right) Densitometric analysis of transporter protein that was newly targeted to the cell surface (newly synthesized and previously internalized protein combined) as a percentage of the total initially biotinylated OATP1A2 at the cell surface. (C) OATP1A2 recycling process. (Left) OATP1A2 recycling was assessed as described in the Materials and Methods. Cells were pretreated with compound $\mathrm{C}$ or DMSO $\left(10 \mu \mathrm{M}, 60\right.$ minutes, $\left.37^{\circ} \mathrm{C}\right)$. Cells were allowed to internalize for 1 minute at $37^{\circ} \mathrm{C}$, and after the first stripping step, cells were allowed to internalize for 1,2 , or 3 minutes at $37^{\circ} \mathrm{C}$. (Right) Densitometric analysis of recycled transporter protein as a percentage of the total initially biotinylated OATP1A2 at the cell surface before initiation of recycling (the protein signal at $t=0$ minutes was subtracted from each time point). A representative blot is presented; each experiment was repeated on three occasions. Values are the mean \pm S.D. $(n=3)$. ** $P<0.01$, different from DMSO-control. NC, vector-transfected HEK-293T cells; SC, stripping control.

small interfering RNA) as compared with the acute effect induced by compound C (60-minute treatment).

We further treated HEK-293T cells with cycloheximide $(100 \mu \mathrm{g} / \mathrm{ml})$ in a time-course experiment to inhibit protein synthesis. As shown in Fig. 5E, AMPK $\alpha 1$ silencing impaired OATP1A2 stability by accelerating the degradation of the transporter protein.

\section{Discussion}

OATP1A2 is abundantly located in the epithelium of many tissues and influences the disposition of numerous drugs, xenobiotics, and endobiotics (Kullak-Ublick et al., 1995; Steckelbroeck et al., 2004; Liu and Li, 2014). At the apical membrane of renal tubular cells, OATP1A2 mediates the reabsorption of xenobiotics (Lee et al., 2005); in the biliary epithelium, OATP1A2 facilitates the excretion of xenobiotics into bile; and at the luminal membrane of the blood-brain barrier, OATP1A2 modulates the uptake of opioid analgesic peptides and other central nervous system-active agents into the brain (Liu et al., 2015). More recently, OATP1A2 has been detected on the apical membrane of the retinal pigment epithelium, where it facilitates the uptake of retinoids (Chan et al., 2015b; Gao et al., 2015). Therefore, OATP1A2 dysfunction may impair drug pharmacokinetics and disposition that could influence the outcomes of drug therapy and may also impair endobiotic uptake into target tissues.

AMPK is an established regulator of metabolic homeostasis because it modulates the expression and function of proteins that control energy production and utilization (Ronnebaum et al., 2014). There is evidence that AMPK regulates epithelial ion transporters of physiologic importance. For instance, AMPK phosphorylates the renal-specific $\mathrm{Na}^{+}-\mathrm{K}^{+}-2 \mathrm{Cl}^{-}$cotransporter (SLC12A1) and the cystic fibrosis transmembrane conductance regulator (ABCC7), as well as the proximal tubule vacuolar $\mathrm{H}^{+}$-ATPase (Hallows et al., 2003; Fraser et al., 2007; Al-bataineh et al., 2014). Through two independent approaches (chemical inhibition and small interfering RNA knockdown), the present findings now indicate that the SLC transporter OATP1A2, which is important in drug disposition, is also potentially regulated by AMPK signaling. Dysregulation was selective for OATP1A2 because the activity of three other major drug-transporting OATPs was unchanged by treatment of cells with the AMPK inhibitor compound 
A

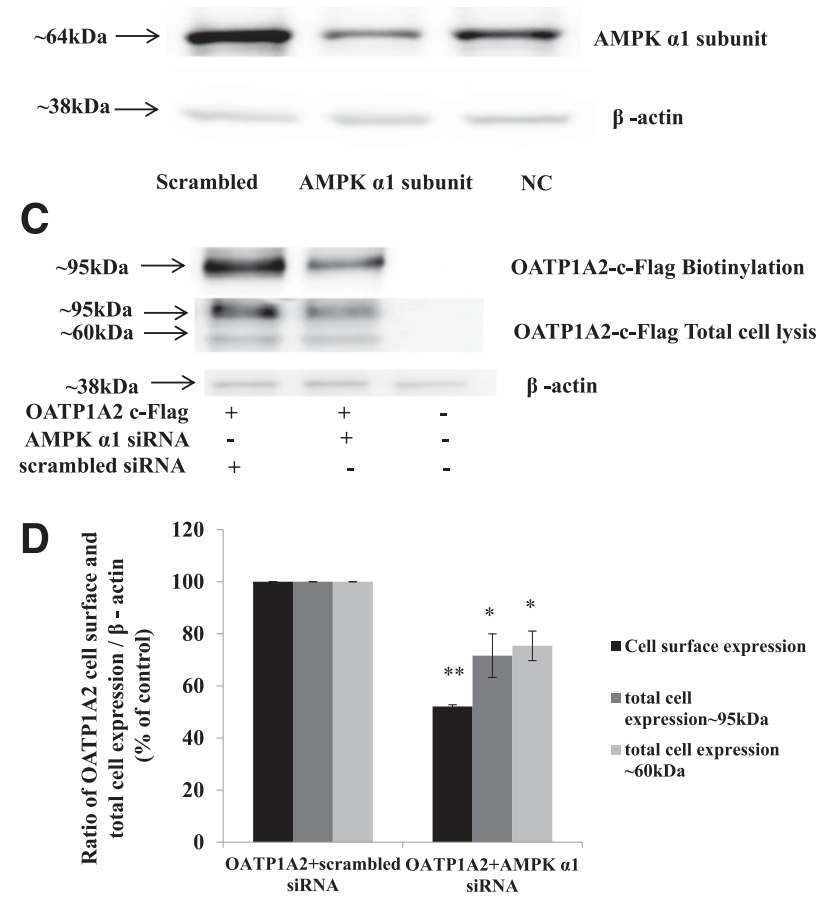

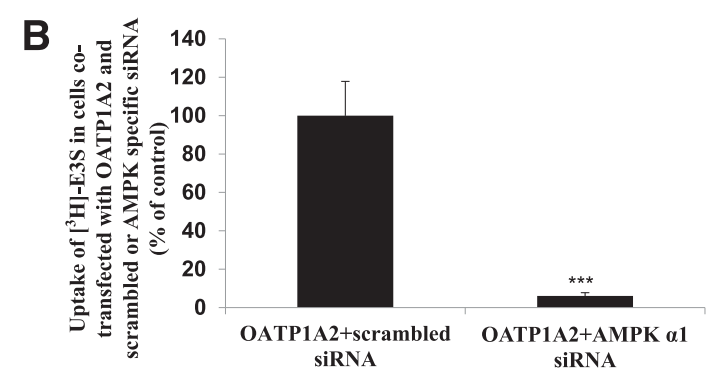

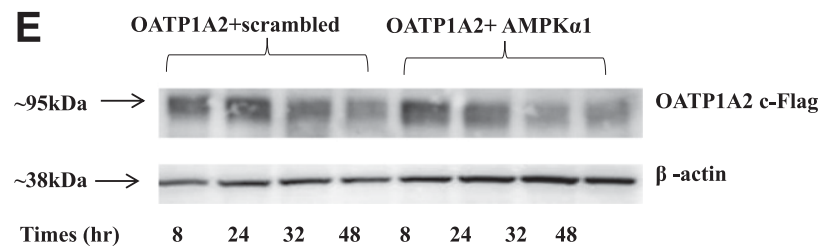

$\begin{array}{lllllllll}\text { Times (hr) } & 8 & 24 & 32 & 48 & 8 & 24 & 32 & 48\end{array}$

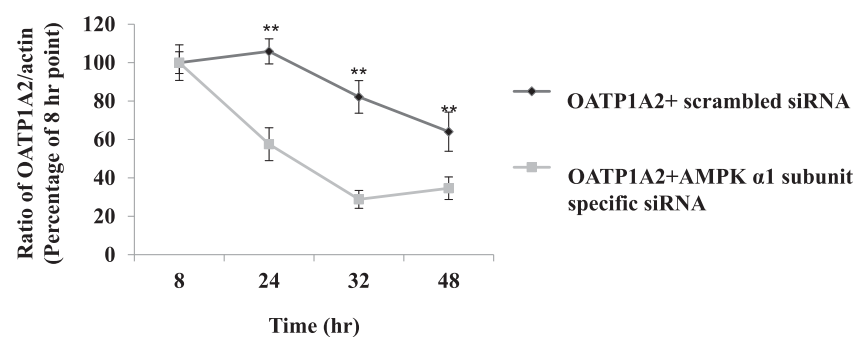

Fig. 5. The effect of AMPK $\alpha 1$-subunit silencing on the uptake function and protein expression of OATP1A2. (A) Total cellular expression of AMPK $\alpha 1$-subunit in HEK-293T cells that overexpressed OATP1A2 after transfection with an AMPK $\alpha 1$-specific or scrambled small interfering RNAs. (Top) Immunoblot was probed with anti-AMPK $\alpha 1$ antibody. (Bottom) After stripping, the blot was reprobed with anti- $\beta$-actin antibody. (B) [ $\left.{ }^{3} \mathrm{H}\right]$-E3S uptake was performed in HEK-293T cells that overexpressed OATP1A2 and were transfected with either AMPK $\alpha 1$-specific or scrambled small interfering RNAs. $* * * P<0.005$, different from scrambled small interfering RNA transfected control. (C) Total cellular and plasma membrane expression of OATP1A2 in HEK-293T cells that overexpressed OATP1A2 and were transfected with either AMPK $\alpha 1$-specific or scrambled small interfering RNAs. (Top) OATP1A2 cell-surface expression evaluated via biotinylation analysis. (Middle) Total cellular expression of OATP1A2 assessed by immunoblotting. (Bottom) After stripping, the blot from the middle panel was reprobed with an anti- $\beta$-actin antibody. (D) Densitometric analysis of OATP1A2 cell-surface and total cell expression. Data were derived in three independent experiments. Values are the mean \pm S.D. $(n=3)$. $* P<0.05$; $* * P<0.01$; different from scrambled small interfering RNA transfected control. (E) Stability of OATP1A2 protein with or without AMPK silencing. HEK-293T cells that overexpressed OATP1A2 were transfected with either AMPK $\alpha 1$-specific or scrambled small interfering RNAs and were treated with the protein synthesis inhibitor cycloheximide $(100 \mu \mathrm{g} / \mathrm{ml})$ for varying times as shown. Immunoblotting analysis was conducted to analyze expression of OATP1A2. (Top) Total cellular expression of OATP1A2 after cycloheximide treatment. (Middle) After stripping, the blot was reprobed with anti- $\beta$-actin antibody. (Bottom) Densitometric analysis of the ratio of OATP1A2 to $\beta$-actin as a percentage of that at the 8-hour time point. A representative blot is presented; each experiment was repeated on three occasions. Values are the mean \pm S.D. $(n=3)$. ${ }^{* *} P<0.01$, different from scrambled small interfering RNA transfected control. NC, vector-transfected HEK-293T cells.

C (Fig. 1A). This also indicated that the regulatory effect of AMPK on OATP1A2 is not likely due to the changes in cellular energy hemostasis.

Kinetic analysis indicated that the maximal rate of E3S uptake by OATP1A2 was decreased by AMPK inhibition, whereas the apparent affinity of the transporter for E3S was unchanged (Fig. 2). Expression of OATP1A2 at the plasma membrane, but not its total cellular expression, was decreased by compound $\mathrm{C}$ treatment, which is consistent with altered trafficking of the transporter (Fig. 3). Using a series of trafficking protocols, we found that AMPK inhibition and silencing increased the internalization and decreased the recycling of OATP1A2 (Fig. 4). In addition to the decrease in OATP1A2 transport function and cell-surface expression, the stability of the transporter protein was also impaired by AMPK $\alpha 1$ silencing (Fig. 5). Taken together, the present findings indicate that AMPK signaling plays an important role in regulating the internalization, targeting, recycling, and stability of OATP1A2. We also tested the potential significance of the present findings in ex vivo and in vivo settings. As we reported before, OATP1A2 is known to express in human retinal pigmented epithelial cells (Chan et al., 2015b; Xu et al., 2016); therefore, we evaluated the response of OATP1A2 to AMPK inhibition in human primary retinal pigmented epithelial cells (Supplemental Fig. 3A). Consistently, OATP1A2mediated $\left[{ }^{3} \mathrm{H}\right]-\mathrm{E} 3 \mathrm{~S}$ uptake was statistically significantly reduced upon compound $\mathrm{C}$ pretreatment $(P<0.05)$, which suggested that OATP1A2 response to AMPK inhibition is not restricted in renal cells. Although there are no direct rodent orthologs of human OATP1A2, mouse Oatp1 (Oatp1a1) has $\sim 70 \%$ similarity to OATP1A2 at the amino acid level. We found that the transport function in HEK-293T cells that overexpressed mouse Oatp1 was decreased by treatment with the AMPK inhibitor compound C. Further, the expression of immunoreactive Oatp1 protein was decreased in the liver of male AMPK $\beta 1-$ null mice (Dzamko et al., 2010; Mount et al., 2012) (Supplemental Fig. 3). AMPK dysregulation has been widely indicated in obesity, diabetes, and the metabolic syndrome (Steinberg and Kemp, 2009; Coughlan et al., 2014), and decreased mouse Oatp1 expression was reported in diabetic rodent models by us and others (Xu et al., 2015; Li et al., 2017), so our study is clinically relevant to elucidate the altered drug 
response in these diseases. Moreover, we acknowledge that under the physiologic condition, the regulatory machinery of AMPK may react differently from that observed in the overexpressing in vitro system, so future studies may verify our findings in in vivo models.

The consensus AMPK phosphorylation motif spans $\sim 11$ amino acid residues and consists of a central Ser/Thr/Tyr residue with one or more basic residues (Arg/Lys/His) at the $\mathrm{N}$-terminal end and one or more hydrophobic residues (e.g., $\mathrm{Leu} / \mathrm{Met} / \mathrm{Ile} / \mathrm{Val} / \mathrm{Phe}$ ) (Hardie, 2011a). Inspection of the primary amino acid sequence of OATP1A2 identified Ser-36 and Ser-313 as potential AMPK phosphorylation sites; the other three drug-transporting OATP isoforms that were evaluated in the present study lacked analogous serine residues (Supplemental Fig. 4A). We tested the functional roles of Ser-36 and Ser-313 using site-directed mutagenesis. However, E3S uptake by the mutagenized OATP1A2 transporters was unchanged from wild type, which suggests either that AMPK does not mediate OATP1A2 phosphorylation directly or that atypical AMPK regulatory sites might be involved (Supplemental Fig. $4 \mathrm{~B})$. As for the previous reports, the protein trafficking of OATPs is also facilitated by other chaperon proteins, such as PDZ-domain containing proteins (Zheng et al., 2014; Murray and Zhou, 2017; Ferreira et al., 2018); therefore, it is plausible that AMPK inhibition impacts on chaperon proteins and indirectly influences the expression and function of OATP1A2. Further studies to explore the impact of AMPK inhibition on these chaperon proteins and the potential atypical AMPK motifs in OATP1A2 are now warranted.

The interplay between multiple kinases modulates the dynamic trafficking of a number of transport proteins. The internalization of glucose transporter 4 (GLUT4; SLC2A4) was impaired and its expression at the plasma membrane of skeletal muscle cells was increased by activation of AMPK and
PKC (Antonescu et al., 2008; Klip et al., 2009). In contrast, expression of the creatine transporter (SLC6A8) was decreased by AMPK and PKC activation (Li et al., 2010), and we found previously that OATP1A2 trafficking was regulated by PKC and CKII (Fig. 6) (Zhou et al., 2011; Chan et al., 2016; Murray and Zhou, 2017). Similar to AMPK inhibition, PKC activation accelerated the internalization of OATP1A2. Although PKC activation did not influence OATP1A2 recycling/targeting, AMPK inhibition also decreased the recycling and membrane targeting of the transporter. Thus, it is feasible that the regulatory actions of $\mathrm{PKC}$ on OATP1A2 could be related in part to AMPK signaling. Similarities between AMPK and CKII inhibition were noted because both decreased OATP1A2 recycling and targeting (Fig. 6) (Chan et al., 2016). However, unlike AMPK inhibition, CKII inhibition impaired the internalization of OATP1A2. Overall, the regulatory effects of CK2 and PKC only partially overlapped with that of AMPK. Thus, OATP1A2 protein trafficking is subject to complex regulations by a group of kinases including AMPK, PKC, and CKII, but AMPK was unlikely the "master" regulatory signaling upstream of PKC or CK2. The main focus of our current study was to explore how OATP1A2 was regulated by AMPK, which influences drug performance in disease treatments; therefore, detailed AMPK signaling pathway mapping involved in this regulation or exploration of the potential atypical AMPK motifs involved in such regulation is beyond the scope of this study and has less relevance to drug treatments, which will be included in our future studies.

In summary, the present study is the first to demonstrate a regulatory role for $\mathrm{AMPK}$ on human drug-transporting OATPs. AMPK regulated the expression and function of OATP1A2 by modulating its subcellular trafficking and stability. The dysregulation of AMPK has been associated with obesity, type II diabetes, and other manifestations of the

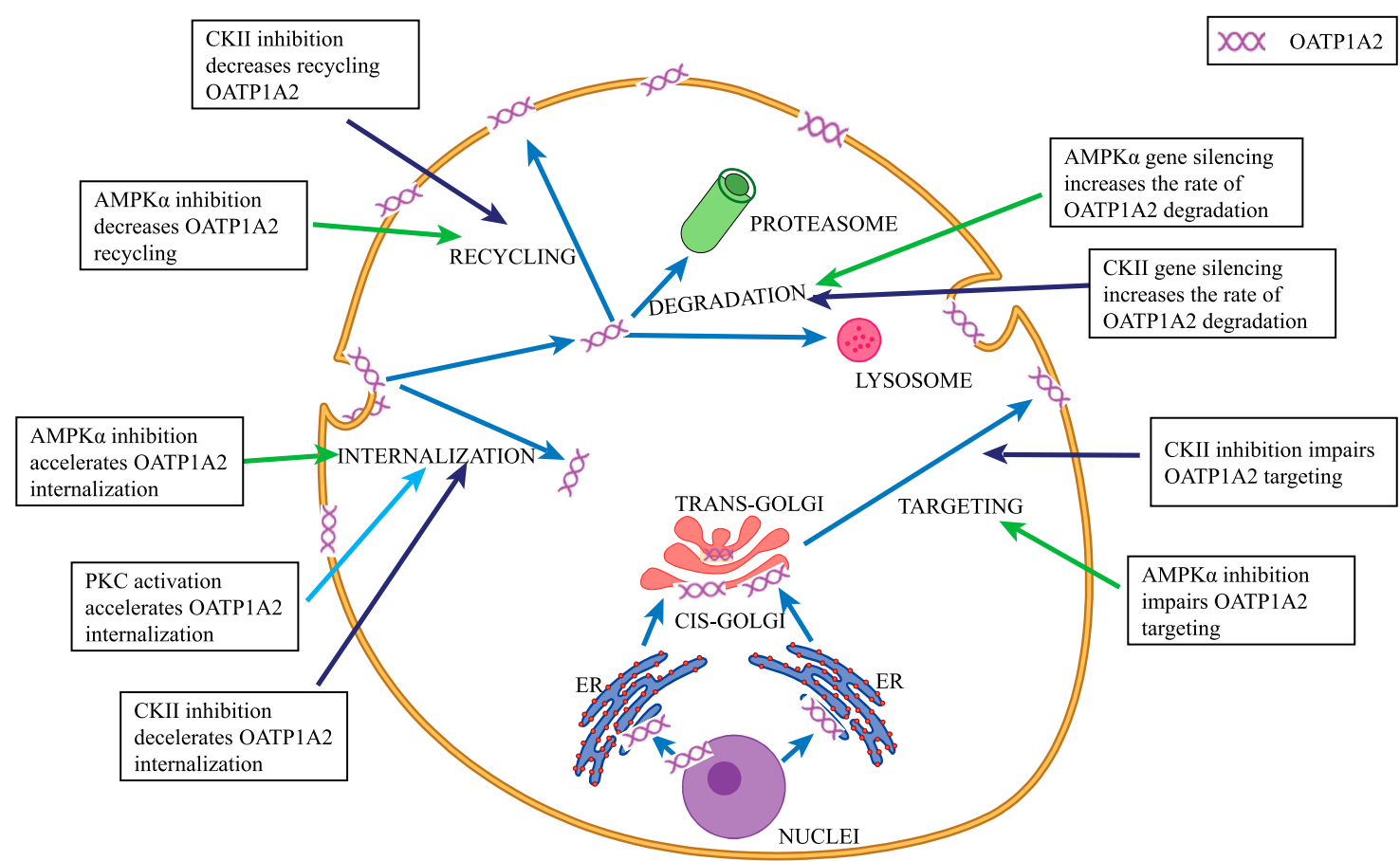

Fig. 6. Multiple signaling kinases regulate the membrane targeting, internalization, recycling, and degradation of OATP1A2. CIS, cisternae; ER, endoplasmic reticulum. 
metabolic syndrome, such as nonalcoholic fatty liver disease. Indeed, the present findings are compatible with those of Clarke et al. (2017), who reported that transporter $N$-glycosylation and trafficking were impaired in nonalcoholic fatty liver disease. Drug therapy may be complicated in patients with obesity or the metabolic syndrome. For example, obesity is associated with a higher incidence of chronic myelogenous leukemia, for which the OATP1A2 substrate imatinib is a front-line treatment (Strom et al., 2009). The present information provides the basis for future studies on how OATP transport activity is regulated in disease. This information could be taken into consideration in drug selection for optimal therapy in patients with the metabolic syndrome.

\section{Acknowledgments}

We thank Bruce E. Kemp from the Department of Medicine, University of Melbourne, Australia, for generously providing the AMPK $\beta 1$-subunit knockout mice samples.

\section{Authorship Contributions}

Participated in research design: Lu, Zhou.

Conducted experiments: Lu, Chan, Cheng, Shams, Zhou.

Contributed new reagents or analytic tools: Murray.

Performed data analysis: Lu, Zhu, Murray, Zhou.

Wrote or contributed to the writing of the manuscript: Lu, Zhu, Murray, Zhou.

\section{References}

Al-bataineh MM, Gong F, Marciszyn AL, Myerburg MM, and Pastor-Soler NM (2014) Regulation of proximal tubule vacuolar $\mathrm{H}(+)$-ATPase by PKA and AMP-activated protein kinase. Am J Physiol Renal Physiol 306:F981-F995.

Antonescu CN, Díaz M, Femia G, Planas JV, and Klip A (2008) Clathrin-dependent and independent endocytosis of glucose transporter 4 (GLUT4) in myoblasts: regulation by mitochondrial uncoupling. Traffic 9:1173-1190.

Beg ZH, Allmann DW, and Gibson DM (1973) Modulation of 3-hydroxy-3-methylglutaryl coenzyme A reductase activity with cAMP and wth protein fractions of rat liver cytosol. Biochem Biophys Res Commun 54:1362-1369.

Carlson CA and Kim KH (1973) Regulation of hepatic acetyl coenzyme A carboxylase by phosphorylation and dephosphorylation. J Biol Chem 248:378-380.

Chan T, Cheung FS, Zheng J, Lu X, Zhu L, Grewal T, Murray M, and Zhou F (2016) Casein kinase 2 is a novel regulator of the human organic anion transporting polypeptide 1A2 (OATP1A2) trafficking. Mol Pharm 13:144-154.

Chan T, Zheng J, Zhu L, Grewal T, Murray M, and Zhou F (2015a) Putative transmembrane domain 6 of the human organic anion transporting polypeptide 1A2 (OATP1A2) influences transporter substrate binding, protein trafficking, and quality control. Mol Pharm 12:111-119.

Chan T, Zhu L, Madigan MC, Wang K, Shen W, Gillies MC, and Zhou F (2015b) Human organic anion transporting polypeptide 1A2 (OATP1A2) mediates cellular uptake of all-trans-retinol in human retinal pigmented epithelial cells. $\mathrm{Br} J$ Pharmacol 172 2343-2353.

Clarke JD, Novak P, Lake AD, Hardwick RN, and Cherrington NJ (2017) Impaired $\mathrm{N}$-linked glycosylation of uptake and efflux transporters in human non-alcoholic fatty liver disease. Liver Int 37:1074-1081.

Coughlan KA, Valentine RJ, Ruderman NB, and Saha AK (2013) Nutrient excess in AMPK downregulation and insulin resistance. J Endocrinol Diabetes Obes 1:1008. Coughlan KA, Valentine RJ, Ruderman NB, and Saha AK (2014) AMPK activation: a therapeutic target for type 2 diabetes? Diabetes Metab Syndr Obes 7:241-253.

Dzamko N, van Denderen BJ, Hevener AL, Jørgensen SB, Honeyman J, Galic S Chen ZP, Watt MJ, Campbell DJ, Steinberg GR, et al. (2010) AMPK beta1 deletion reduces appetite, preventing obesity and hepatic insulin resistance. J Biol Chem 285:115-122.

Ferreira C, Hagen P, Stern M, Hussner J, Zimmermann U, Grube M, and Meyer Zu Schwabedissen HE (2018) The scaffold protein PDZK1 modulates expression and function of the organic anion transporting polypeptide 2B1. Eur J Pharm Sci 120: 181-190.

Fraser SA, Gimenez I, Cook N, Jennings I, Katerelos M, Katsis F, Levidiotis V, Kemp $\mathrm{BE}$, and Power DA (2007) Regulation of the renal-specific $\mathrm{Na}+\mathrm{K}+-2 \mathrm{Cl}$ co-transporter NKCC2 by AMP-activated protein kinase (AMPK). Biochem J 405: 85-93.

Gao B, Vavricka SR, Meier PJ, and Stieger B (2015) Differential cellular expression of organic anion transporting peptides OATP1A2 and OATP2B1 in the human retina and brain: implications for carrier-mediated transport of neuropeptides and neurosteriods in the CNS. Pflugers Arch 467:1481-1493.

Hallows KR, McCane JE, Kemp BE, Witters LA, and Foskett JK (2003) Regulation of channel gating by AMP-activated protein kinase modulates cystic fibrosis transmembrane conductance regulator activity in lung submucosal cells. J Biol Chem 278:998-1004.

Handa N, Takagi T, Saijo S, Kishishita S, Takaya D, Toyama M, Terada T, Shirouzu M, Suzuki A, Lee S, et al. (2011) Structural basis for compound C inhibition of the human AMP-activated protein kinase $\alpha 2$ subunit kinase domain. Acta Crystallogr D Biol Crystallogr 67:480-487.

Hardie DG (2011a) AMP-activated protein kinase: an energy sensor that regulates all aspects of cell function. Genes Dev 25:1895-1908.

Hardie DG (2011b) Sensing of energy and nutrients by AMP-activated protein kinase. Am $J$ Clin Nutr 93:891S-896S.

Hardie DG, Ross FA, and Hawley SA (2012) AMPK: a nutrient and energy sensor that maintains energy homeostasis. Nat Rev Mol Cell Biol 13:251-262.

Hediger MA, Romero MF, Peng JB, Rolfs A, Takanaga H, and Bruford EA (2004) The ABCs of solute carriers: physiological, pathological and therapeutic implications of human membrane transport proteinsIntroduction. Pflugers Arch 447:465-468.

Hong M, Hong W, Ni C, Huang J, and Zhou C (2015) Protein kinase C affects the internalization and recycling of organic anion transporting polypeptide $1 \mathrm{~B} 1$. Biochim Biophys Acta 1848 (10 Pt A):2022-2030.

Jigorel E, Le Vee M, Boursier-Neyret C, Parmentier Y, and Fardel O (2006) Differential regulation of sinusoidal and canalicular hepatic drug transporter expression by xenobiotics activating drug-sensing receptors in primary human hepatocytes. Drug Metab Dispos 34:1756-1763.

Johnston RA, Rawling T, Chan T, Zhou F, and Murray M (2014) Selective inhibition of human solute carrier transporters by multikinase inhibitors. Drug Metab Dispos 42:1851-1857.

Kim RB (2003) Organic anion-transporting polypeptide (OATP) transporter family and drug disposition. Eur J Clin Invest 33 (Suppl 2):1-5.

Klip A, Schertzer JD, Bilan PJ, Thong F, and Antonescu C (2009) Regulation of glucose transporter 4 traffic by energy deprivation from mitochondrial compromise. Acta Physiol (Oxf) 196:27-35.

Köck K, Koenen A, Giese B, Fraunholz M, May K, Siegmund W, Hammer E, Völker U, Jedlitschky G, Kroemer HK, et al. (2010) Rapid modulation of the organic anion transporting polypeptide 2B1 (OATP2B1, SLCO2B1) function by protein kinase C-mediated internalization. J Biol Chem 285:11336-11347.

Kullak-Ublick GA, Hagenbuch B, Stieger B, Schteingart CD, Hofmann AF, Wolkoff AW, and Meier PJ (1995) Molecular and functional characterization of an organic anion transporting polypeptide cloned from human liver. Gastroenterology 109:1274-1282.

Lee W, Glaeser H, Smith LH, Roberts RL, Moeckel GW, Gervasini G, Leake BF, and Kim RB (2005) Polymorphisms in human organic anion-transporting polypeptide 1A2 (OATP1A2): implications for altered drug disposition and central nervous system drug entry. J Biol Chem 280:9610-9617.

Li F, Ling ZL, Wang ZJ, Zhong ZY, Shu N, Zhang M, Liu C, Liu L, and Liu XD (2017) Differential effects of pravastatin on the pharmacokinetics of paroxetine in normal and diabetic rats. Xenobiotica 47:20-30.

Li H, Thali RF, Smolak C, Gong F, Alzamora R, Wallimann T, Scholz R, Pastor-Soler NM, Neumann D, and Hallows KR (2010) Regulation of the creatine transporter by AMP-activated protein kinase in kidney epithelial cells. Am J Physiol Renal Physiol 299:F167-F177.

Liu H, Yu N, Lu S, Ito S, Zhang X, Prasad B, He E, Lu X, Li Y, Wang F, et al. (2015) Solute carrier family of the organic anion-transporting polypeptides 1A2- MadinDarby canine kidney II: a promising in vitro system to understand the role of organic anion-transporting polypeptide $1 \mathrm{~A} 2$ in blood-brain barrier drug penetration. Drug Metab Dispos 43:1008-1018.

Liu T and Li Q (2014) Organic anion-transporting polypeptides: a novel approach for cancer therapy. $J$ Drug Target 22:14-22.

Liu X, Chhipa RR, Nakano I, and Dasgupta B (2014) The AMPK inhibitor compound $\mathrm{C}$ is a potent AMPK-independent antiglioma agent. Mol Cancer Ther 13:596-605. Lu X, Chan T, Zhu L, Bao X, Velkov T, Zhou QT, Li J, Chan HK, and Zhou F (2018) The inhibitory effects of eighteen front-line antibiotics on the substrate uptake mediated by human organic anion/cation transporters, organic anion transporting polypeptides and oligopeptide transporters in in vitro models. Eur J Pharm Sci 115:132-143.

Ma X, Shah YM, Guo GL, Wang T, Krausz KW, Idle JR, and Gonzalez FJ (2007) Rifaximin is a gut-specific human pregnane $\mathrm{X}$ receptor activator. J Pharmacol Exp Ther 322:391-398.

Meyer zu Schwabedissen HE, Tirona RG, Yip CS, Ho RH, and Kim RB (2008) Interplay between the nuclear receptor pregnane $\mathrm{X}$ receptor and the uptake transporter organic anion transporter polypeptide $1 \mathrm{~A} 2$ selectively enhances estrogen effects in breast cancer. Cancer Res 68:9338-9347.

Mihaylova MM and Shaw RJ (2011) The AMPK signalling pathway coordinates cell growth, autophagy and metabolism. Nat Cell Biol 13:1016-1023.

Mount PF, Gleich K, Tam S, Fraser SA, Choy SW, Dwyer KM, Lu B, Denderen BV Fingerle-Rowson G, Bucala R, et al. (2012) The outcome of renal ischemiareperfusion injury is unchanged in AMPK- $\beta 1$ deficient mice. PLoS One 7:e29887.

Murray M and Zhou F (2017) Trafficking and other regulatory mechanisms for organic anion transporting polypeptides and organic anion transporters that modulate cellular drug and xenobiotic influx and that are dysregulated in disease. Br J Pharmacol 174:1908-1924.

O'Neill HM, Holloway GP, and Steinberg GR (2013) AMPK regulation of fatty acid metabolism and mitochondrial biogenesis: implications for obesity. Mol Cell Endocrinol 366:135-151.

Ronnebaum SM, Patterson C, and Schisler JC (2014) Minireview: hey U(PS): metabolic and proteolytic homeostasis linked via AMPK and the ubiquitin proteasome system. Mol Endocrinol 28:1602-1615.

Russo GL, Russo M, and Ungaro P (2013) AMP-activated protein kinase: a target for old drugs against diabetes and cancer. Biochem Pharmacol 86:339-350.

Shams T, Lu X, Zhu L, and Zhou F (2018) The inhibitory effects of five alkaloids on the substrate transport mediated through human organic anion and cation transporters. Xenobiotica 48:197-205.

Steckelbroeck S, Nassen A, Ugele B, Ludwig M, Watzka M, Reissinger A, Clusmann H, Lütjohann D, Siekmann L, Klingmüller D, et al. (2004) Steroid sulfatase (STS) expression in the human temporal lobe: enzyme activity, mRNA expression and immunohistochemistry study. J Neurochem 89:403-417.

Steinberg GR and Kemp BE (2009) AMPK in health and disease. Physiol Rev 89: 1025-1078. 
Strom SS, Yamamura Y, Kantarijian HM, and Cortes-Franco JE (2009) Obesity, weight gain, and risk of chronic myeloid leukemia. Cancer Epidemiol Biomarkers Prev 18:1501-1506.

Tangeman L, Wyatt CN, and Brown TL (2012) Knockdown of AMP-activated protein kinase alpha 1 and alpha 2 catalytic subunits. J RNAi Gene Silencing 8:470-478

Tzatsos A and Tsichlis PN (2007) Energy depletion inhibits phosphatidylinositol 3-kinase/Akt signaling and induces apoptosis via AMP-activated protein kinasedependent phosphorylation of IRS-1 at Ser-794. J Biol Chem 282:18069-18082.

Xu C, Zhu L, Chan T, Lu X, Shen W, Gillies MC, and Zhou F (2015) The altered rena and hepatic expression of solute carrier transporters (SLCs) in type 1 diabetic mice. PLoS One 10:e120760.

Xu C, Zhu L, Chan T, Lu X, Shen W, Madigan MC, Gillies MC, and Zhou F (2016) Chloroquine and hydroxychloroquine are novel inhibitors of human organic anion transporting polypeptide 1A2. J Pharm Sci 105:884-890.

Xu F, Li Z, Zheng J, Gee Cheung FS, Chan T, Zhu L, Zhuge H, and Zhou F (2013) The inhibitory effects of the bioactive components isolated from Scutellaria baicalensis on the cellular uptake mediated by the essential solute carrier transporters. J Pharm Sci 102:4205-4211.

Zheng J, Chan T, Cheung FS, Zhu L, Murray M, and Zhou F (2014) PDZK1 and NHERF1 regulate the function of human organic anion transporting polypeptide
1A2 (OATP1A2) by modulating its subcellular trafficking and stability. PLoS One 9:e94712.

Zhou F, Lee AC, Krafczyk K, Zhu L, and Murray M (2011) Protein kinase C regulates the internalization and function of the human organic anion transporting polypeptide 1A2. Br J Pharmacol 162:1380-1388.

Zhou F, Zheng J, Zhu L, Jodal A, Cui PH, Wong M, Gurney H, Church WB, and Murray M (2013) Functional analysis of novel polymorphisms in the human SLCO1A2 gene that encodes the transporter OATP1A2. AAPS J 15:1099-1108.

Zhou F, Zhu L, Cui PH, Church WB, and Murray M (2010) Functional characterization of nonsynonymous single nucleotide polymorphisms in the human organic anion transporter 4 (hOAT4). Br J Pharmacol 159:419-427.

Zhou F, Zhu L, Wang K, and Murray M (2017) Recent advance in the pharmacogenomics of human solute carrier transporters (SLCs) in drug disposition. Adv Drug Deliv Rev 116:21-36.

Address correspondence to: Fanfan Zhou, School of Pharmacy, Faculty of Medicine and Health, The University of Sydney, NSW 2006, Australia. E-mail: Fanfan.zhou@sydney.edu.au 